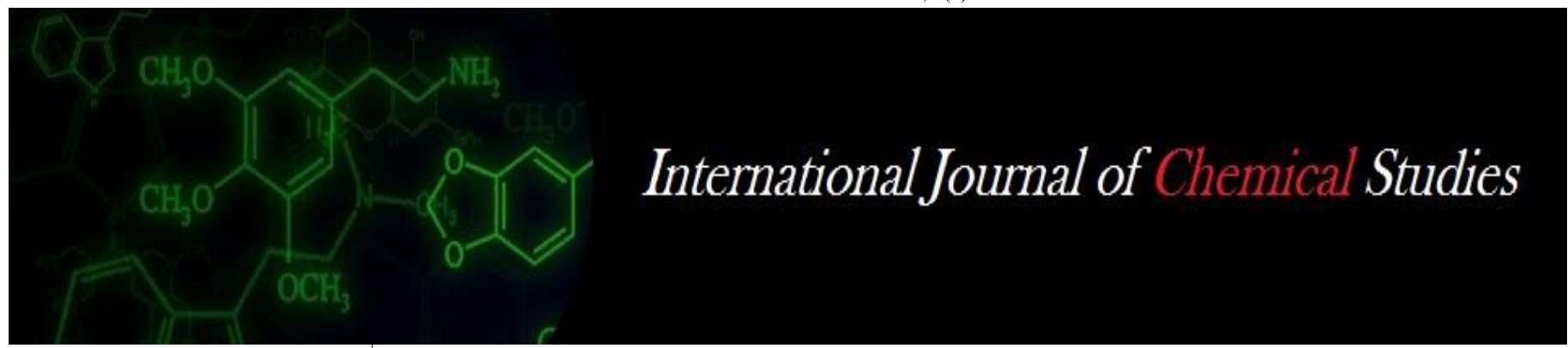

P-ISSN: 2349-8528

E-ISSN: 2321-4902

www.chemijournal.com

IJCS 2020; 8(3): 225-228

(C) 2020 IJCS

Received: 25-03-2020

Accepted: 27-04-2020

Vivek Kamat

CCSHAU Hisar, Haryana, India

Jay Harendrasinh Sisodiya

College of Agricultural

Engineering and Technology,

Junagadh, Gujarat, India

Manoj Kumar Mahawar

HCP Division, ICAR-CIPHET

Abohar, Punjab, India

Kirti Jalgaonkar

HCP Division, ICAR-CIPHET

Abohar, Punjab, India

\section{Determination of some physical properties of Plum (cv. Kala Amritsari) fruits}

\author{
Vivek Kamat, Jay Harendrasinh Sisodiya, Manoj Kumar Mahawar and \\ Kirti Jalgaonkar
}

DOI: https://doi.org/10.22271/chemi.2020.v8.i3c.9230

\begin{abstract}
The present study was carried out to determine the physical properties of plum ( $c v$. Kala Amritsari) which will be helpful for the design of fruit processing machineries. The fruits were graded in two categories viz. smaller (S) and bigger (B) on the basis of physical appearance. Moisture content of the fruit pulp was $85.19 \pm 0.54 \%$ (w.b). Linear dimensions of ' $S$ ' fruits were: major intercept $(19.41 \pm 1.96$ $\mathrm{mm})$, minor intercept $(16.79 \pm 1.46 \mathrm{~mm})$, geometric mean diameter $(18.48 \pm 1.72 \mathrm{~mm})$, arithmetic mean diameter $(3.31 \pm 0.12 \mathrm{~mm})$, sphericity $(0.79 \pm 0.03)$, surface area $\left(1082.59 \pm 120.81 \mathrm{~mm}^{2}\right)$ and aspect ratio (1.15 \pm 0.17$)$, while the corresponding values for ' $B$ ' fruit were, $25.15 \pm 0.77 \mathrm{~mm}, 23.61 \pm 0.30 \mathrm{~mm}$, $24.49 \pm 0.41 \mathrm{~mm}, 3.17 \pm 0.08 \mathrm{~mm}, 0.98 \pm 0.02,1901.98 \pm 66.93 \mathrm{~mm}^{2}, 1.08 \pm 0.15$, respectively. The density values in terms of bulk density were $660 \pm 27.54 \mathrm{kgm}^{-3}(\mathrm{~S}), 473 \pm 18.69 \mathrm{kgm}^{-3}(\mathrm{~B})$, true density $1213 \pm 58.3$ $\mathrm{kgm}^{-3}(\mathrm{~S}), 1120 \pm 47.28 \mathrm{kgm}^{-3}(\mathrm{~B})$ and porosity $45.6 \pm 5.30$ (S), 56.8 \pm 7.28 (B) were also recorded. Colour values in terms of $\mathrm{L}(33.62 \pm 2.04)$, a $(66.87 \pm 6.75), \mathrm{b}(10.24 \pm 2.62)$ for ' $\mathrm{S}$ ' fruits and for ' $\mathrm{B}$ ' fruits $\mathrm{L}$ $(37.38 \pm 1.88)$, a $(61.25 \pm 5.91)$ and $\mathrm{b}(12.28 \pm 2.66)$ were observed. The average fruit weight, pulp weight and seed weight for ' $\mathrm{S}$ ' grade fruits was $32.35 \pm 4.25 \mathrm{~g}, 28.74 \pm 3.50 \mathrm{~g}, 1.09 \pm 0.32 \mathrm{~g}$, while for ' $\mathrm{B}$ ' grade fruits it was $38.14 \pm 5.33 \mathrm{~g}, 33.57 \pm 6.53 \mathrm{~g}, 1.73 \pm 0.26$, respectively.
\end{abstract}

Keywords: Grade, plum, physical properties, moisture content

\section{Introduction}

Physical characteristics of agricultural products are the most important parameters in design of grading, conveying, processing and packaging systems. Among these physical characteristics, mass, volume, projected areas and center of gravity are the most important ones in sizing systems. Axial dimensions viz. length, width and thickness are also basic and important parameters considered for machine design (Mohsenin, 1986) ${ }^{[6]}$.

Plums (Prunus domestica) are the stony fruits wide produced within the Asians countries. In India, plum has been cultivated on 0.23 million hectare area with production of 0.89 milliton tons (Anonymous, 2019) ${ }^{[1]}$. The major plum growing states includes Jammu and Kashmir, Himachal Pradesh, Uttar Pradesh, Uttarakhand, Arunachal Pradesh, Nagaland, Meghalaya, Manipur and Sikkim. They are available in an exceedingly wide variety of size and colours like yellow, white, green or red pulp. The fruits are typically of medium size (1-3 inches in diameter) and are usually spherical/oval in shape with firm pulp and juicy nature. Plum fruit is rich in Vitamin A, B, (Thiamine), riboflavin and some minerals like calcium, phosphorus and iron. Plums are considered to be an ample source of nutrients and health beneficial compounds (Rop et al. 2009) ${ }^{[8]}$. The well blended acidity with sugars is helpful in the preparation of jams and squashes. Plums are considered a source of phytochemical compounds with helpful effects on health. Plums $c v$. Kala Amritsari are medium in size, dark brown at maturity while pulp is slightly yellowish and juicy most suitable for preparation of jam.

Several reports are available concerning the quality as well as estimation of physico- chemical properties and anthocyanin content of various plum cultivars (Rop et al. 2009; Usenik et al. 2009; Ionica et al. 2013) ${ }^{[8,9,3]}$. The aim of this paper was to evaluate the physico-chemical properties of plum $c v$. Kala Amritsari with a function of its grade in order to obtain the data helpful for the design of relevant post-harvest machineries.
Corresponding Author: HCP Division, ICAR-CIPHET Abohar, Punjab, India 


\section{Materials and Methods \\ Raw material}

Plum fruits $c v$. Kala Amritsari was harvested at optimum maturity from the orchard of ICAR-CIPHET Abohar (Punjab). The healthy fruits were selected, washed and graded subsequently as big (B) and small (S) based upon the diameter (Fig. 1a and 1b). The fruits were stored in polythene bags in cold storage at $8 \pm 2{ }^{\circ} \mathrm{C}$ until use.

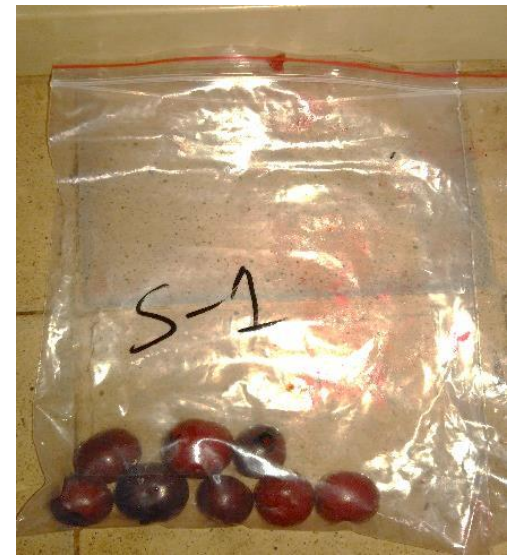

Fig 1a: Smaller (S) grade plum

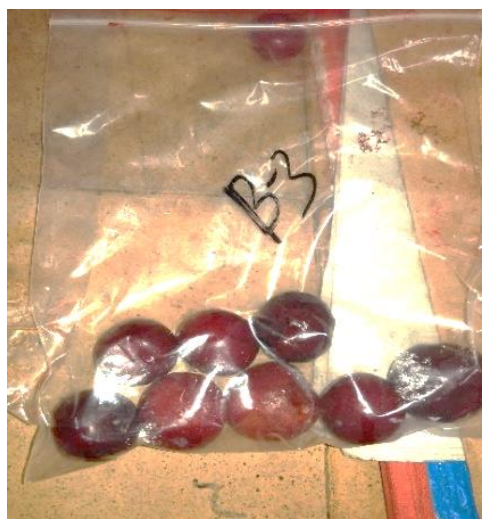

Fig 1b: Bigger (B) grade plum

\section{Determination of physical properties}

The properties including axial dimensions, geometric mean diameter, arithmetic mean diameter, moisture content, true density, bulk density, sphericity, surface area, aspect ratio, porosity, colour, fruit weight, pulp weight and stone weight were estimated following the standard procedures. To determine physical properties of plum fruits are separated by visual appearance and 30 fruits were randomly selected for both small and big fruit group. Axial dimensions (major and minor intercept) were measured using digital vernier calipers (M/s Mitutoyo, $\pm 0.01 \mathrm{~mm}$ ) as shown in Fig. 2.

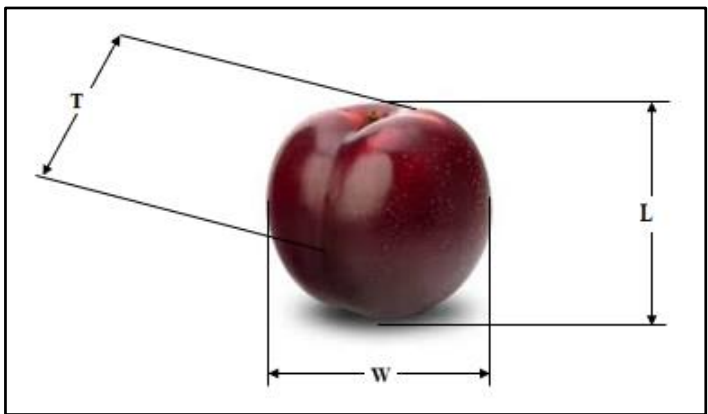

Fig 2: Pictorial representation of the axial dimensions
The moisture content of the pulp was measured using hot air oven method $70 \pm 5{ }^{\circ} \mathrm{C}$ for $24 \mathrm{~h}$. The mass of the fruit was determined using digital balance $(\mathrm{M} / \mathrm{s}$ Metler Toledo, \pm 0.001 g) by taking the weight of 100 randomly selected fruits and then extrapolated to weight of 1000 fruits. The arithmetic mean diameter (AMD) and the geometric mean diameter (GMD), sphericity index $\left(\mathrm{S}_{\mathrm{P}}\right)$ and surface area $(\mathrm{S})$ was calculated using following formulae (Mohsenin $1986^{[6]}$, Mahawar et al. 2017, Mahawar et al. 2019) ${ }^{[6,4,5]}$

$$
\begin{aligned}
& \mathrm{AMD}=\frac{\mathrm{LWT}}{3} \\
& \mathrm{GMD}=(\mathrm{LWT})^{1 / 3} \\
& \mathrm{Sp}=\frac{\mathrm{GMD}}{\mathrm{L}} \times 100 \\
& \mathrm{~S}=\pi(\mathrm{GMD})^{2}
\end{aligned}
$$

The aspect ratio (AR) of the fruit was calculated using following formula (Pathak et al. 2019) ${ }^{[7]}$.

$$
\mathrm{AR}=\frac{\mathrm{W}}{\mathrm{L}}
$$

The volume of the fruit and true density of the fruits were determined using the liquid displacement method. Bulk density was determined by filling fruits in $1000 \mathrm{ml}$ measuring cylinder. The fruits are weighed later and the bulk density was calculated from the mass of the fruits and the volume of measuring cylinder using the following formula:

Bulk density $=\frac{\text { Weight of fruits }}{\text { Volume of fruits }}$

Porosity was determined by following equation (Mohsenin 1986; Pathak et al. 2019) ${ }^{[6,7]}$.

Porosity $=\left[1-\frac{\text { Bulk Density }}{\text { True Density }}\right] \times 100$

Color measurement was carried out using a Hunter colorimeter D25 optical sensor (Hunter Associates Laboratory, Trestoa, VA, USA) on the basis of three variables (L, $a, b$ value). The "L" value signifies the lightness (100 for white and 0 for black), the "a "value represents greenness and redness ( -80 for green and 80 for red) while the " $b$ " value signifies changes from blueness to yellowness (-80 for blue and 80 for yellow). The instrument was calibrated against a standard white reference tile.

\section{Results and Discussion \\ Moisture content}

Moisture content of fruit pulp was found $85.19 \%$ (w.b). Ertekin et al. (2006) ${ }^{[2]}$ reported the moisture content for Stanley and Frenze 90 plums as $89 \%$ (w.b) and $87 \%$ (w.b), respectively.

\section{Axial dimensions and surface area}

For smaller grade fruits, the values observed for major intercept (16.83 to $22.76 \mathrm{~mm}$ ), minor intercept (22.17 to 29.61 $\mathrm{mm})$, arithmetic mean diameter (3.12 to $3.52 \mathrm{~mm}$ ), geometric mean diameter (16.36 to $21.47 \mathrm{~mm}$ ) and surface area $(842.25$ to $1449.65 \mathrm{~mm}^{2}$ ). However, for bigger fruits the corresponding values are 14.69 to $19.13 \mathrm{~mm}, 19.41$ to 29.76 $\mathrm{mm}, 2.72$ to $3.64 \mathrm{~mm}, 21.41$ to $28.80 \mathrm{~mm}$ and 1141.46 to 
$2607.52 \mathrm{~mm}^{2}$, respectively. Ertekin et al. (2006) ${ }^{[2]}$ reported that the average fruit length $(48.25 \mathrm{~mm})$, fruit width $(33.24$ $\mathrm{mm})$, fruit thickness $(31.32 \mathrm{~mm})$ and geometric diameter $(36.48 \mathrm{~mm})$ for cv. Stanley plum and the corresponding values for $c v$. Frenze 90 were $58.33 \mathrm{~mm}, 47.70 \mathrm{~mm}, 45.49$ $\mathrm{mm}$ and $50.00 \mathrm{~mm}$, respectively. The data regarding physical properties is presented in Table 1.

Table 1: Some physical properties of plum $c v$. Kala Amritsari

\begin{tabular}{|c|c|c|c|c|c|c|c|c|}
\hline \multirow{2}{*}{ Properties } & \multicolumn{2}{|c|}{ Min } & \multicolumn{2}{|c|}{ Max } & \multicolumn{2}{|c|}{ Mean } & \multicolumn{2}{|c|}{ Standard Deviation } \\
\hline & Small & Big & Small & Big & Small & Big & Small & Big \\
\hline Major intercept (mm) & 16.83 & 22.17 & 22.76 & 29.61 & 19.41 & 25.15 & 1.96 & 3.71 \\
\hline Minor intercept (mm) & 14.69 & 19.41 & 19.13 & 29.76 & 16.78 & 23.60 & 1.45 & 2.26 \\
\hline Arithmetic mean diameter & 3.12 & 2.72 & 3.52 & 3.64 & 3.31 & 3.17 & 0.12 & 0.29 \\
\hline Geometric mean diameter $(\mathrm{mm})$ & 16.36 & 21.41 & 21.47 & 28.80 & 18.48 & 24.49 & 1.72 & 2.23 \\
\hline Surface area $\left(\mathrm{mm}^{2}\right)$ & 842.25 & 1441.46 & 1449.65 & 2607.52 & 1082.58 & 1901.97 & $7 \quad 120.81$ & $66 . .98$ \\
\hline Bulk density $\left(\mathrm{kgm}^{-3}\right)$ & 615.33 & 373.78 & 680.36 & 496.35 & 660.00 & 473.00 & 27.54 & 18.69 \\
\hline True density $\left(\mathrm{kgm}^{-3}\right)$ & 1150.36 & 978.34 & 1315.37 & 1237.36 & 1213.00 & 1120.00 & 58.90 & 47.28 \\
\hline Sphericity index (\%) & 0.73 & 0.90 & 0.83 & 0.98 & 0.78 & 0.96 & 0.03 & 0.09 \\
\hline Aspect ratio & 1.05 & 0.86 & 1.26 & 1.31 & 1.15 & 1.08 & 0.06 & 0.14 \\
\hline Porosity (\%) & 46.50 & 61.79 & 48.27 & 59.88 & 45.58 & 57.76 & 5.3 & 7.28 \\
\hline Fruit weight $(\mathrm{g})$ & 14.32 & 34.71 & 26.52 & 45.38 & 19.83 & 40.10 & 4.25 & 5.33 \\
\hline Pulp weight (g) & 13.50 & 28.56 & 22.89 & 36.60 & 18.74 & 33.57 & 3.50 & 6.53 \\
\hline Stone weight $(\mathrm{g})$ & 0.79 & 5.86 & 3.63 & 9.33 & 1.09 & 6.53 & 0.32 & 0.26 \\
\hline \multicolumn{9}{|c|}{ Fruit colour } \\
\hline $\mathrm{L}^{*}$ & 32.28 & 30.88 & 36.75 & 53.11 & 34.61 & 39.04 & 2.04 & 1.88 \\
\hline$a^{*}$ & 59.78 & 52.88 & 74.69 & 67.74 & 66.61 & 60.48 & 6.75 & 5.91 \\
\hline $\mathrm{b}^{*}$ & 8.49 & 8.63 & 14.14 & 13.94 & 11.08 & 11.22 & 2.62 & 2.66 \\
\hline
\end{tabular}

Values are represented as average of 30 replications

\section{Bulk and True density}

Bulk density values were 615.33 to $680.36 \mathrm{kgm}^{-3}$ for ' $\mathrm{S}$ ' grade fruits and were 373.78 to $496.35 \mathrm{kgm}^{-3}$ for ' $\mathrm{B}$ ' grade fruits. Ertekin et al. (2006) ${ }^{[2]}$ reported bulk density $\left(642 \mathrm{kgm}^{-}\right.$ ${ }^{3}$ ) and true density $\left(1050 \mathrm{kgm}^{-3}\right)$ for $c v$. Stanley and the corresponding values were $1029 \mathrm{kgm}^{-3}$ and $572 \mathrm{kgm}^{-3}$ for $c v$. Frenze 90.

\section{Sphericity, Aspect Ratio and Porosity}

The average value of sphericity index was $0.78 \%$ and $0.96 \%$ for smaller and bigger grade fruits. The mean porosity values of smaller and bigger plums were observed to be 45.58 and 57.76. The aspect ratio value for smaller and bigger plums was in the range of 1.05 to 1.26 and 0.86 to 1.31 , respectively. Ertekin et al. (2006) ${ }^{[2]}$ reported that the sphericity index, porosity and aspect ratio were $0.76 \%, 38.99 \%$ and 0.69 for $c v$. Stanley and $0.858 \%, 44.25 \%$ and $0.821 \%$ for $c v$. Frenze 90 , respectively.

\section{Fruit mass, Pulp and Stone weight}

Fruit mass was in range of 14.32 to $26.52 \mathrm{~g}(\mathrm{~S})$ and 34.71 to $45.38 \mathrm{~g}$ (B) fruits. The pulp weight and stone weight was varied from 13.50 to $22.89 \mathrm{~g}$ and 0.79 to $3.63 \mathrm{~g}$ for ' $\mathrm{S}$ ' grade of fruits. Similarly, the corresponding values are 28.56 to $36.60 \mathrm{~g}$ (pulp weight) and stone weight (5.86 to $9.33 \mathrm{~g}$ ) for 'B' grade of plums. Ertekin et al. (2006) ${ }^{[2]}$ reported that the average stone mass was $1.93 \mathrm{~g}$ for $c v$. Stanley and $2.64 \mathrm{~g}$ for $c v$. Frenze 90 , respectively.

\section{Colour values}

The average colour values ( $\mathrm{L}$ value) for smaller and bigger plums were 34.61 and 39.04 i.e., bigger fruits are brighter than smaller fruits. The redness value (a) was higher for smaller fruits (66.61) than the bigger fruits (60.48) and light blue (b) value were found higher for bigger fruits (11.22) than the smaller fruits (11.08). The chromatic characteristics are reported to have dependency on the maturity/ripening level of fruits (Usenik et al. 2009) ${ }^{[9]}$.

\section{Conclusion}

- Moisture content of the plum fruit was $85.19 \pm 0.54 \%$ (w.b).

- Linear dimensions of smaller fruits were: major intercept $(19.41 \pm 1.96 \mathrm{~mm})$, minor intercept $(16.79 \pm 1.46 \mathrm{~mm})$, geometric mean diameter $(18.48 \pm 1.72 \mathrm{~mm})$, arithmetic mean diameter $(3.31 \pm 0.12 \mathrm{~mm})$, sphericity $(0.79 \pm 0.03)$, surface area $\left(1082.59 \pm 120.81 \mathrm{~mm}^{2}\right)$ and aspect ratio (1.15 \pm 0.17$)$. Whereas, corresponding values for bigger fruit were, $25.15 \pm 0.77 \mathrm{~mm}, 23.61 \pm 0.30 \mathrm{~mm}, 24.49 \pm 0.41$ $\mathrm{mm}, 3.17 \pm 0.08 \mathrm{~mm}, 0.96 \pm 0.02,1901.98 \pm 66.93 \mathrm{~mm}^{2}$, $1.08 \pm 0.15$, respectively.

- The density values in terms of bulk density (S: $660 \pm 27.54 \mathrm{kgm}^{-3}$, B: $473 \pm 18.69 \mathrm{kgm}^{-3}$ ), true density (S: $1213 \pm 58.3 \mathrm{kgm}^{-3}, \mathrm{~B}: 1120 \pm 47.28 \mathrm{kgm}^{-3}$ ) and porosity (S: 45.6 \pm 5.30 , B: $56.8 \pm 7.28$ ) were observed.

- The average fruit weight, pulp weight and seed weight for ' $\mathrm{S}$ ' grade fruits was $32.35 \pm 4.25 \mathrm{~g}, 28.74 \pm 3.50 \mathrm{~g}$, $1.09 \pm 0.32 \mathrm{~g}$, while for ' $\mathrm{B}$ ' grade fruits it was $38.14 \pm 5.33$ $\mathrm{g}, 33.57 \pm 6.53 \mathrm{~g}, 1.73 \pm 0.26$, respectively.

- Colour values in the form of $L, a, b$ values for ' $S$ ' fruits $(33.62 \pm 2.04,66.87 \pm 6.75,10.24 \pm 2.62)$ and for ' $\mathrm{B}$ ' fruits $(37.38 \pm 1.88,61.25 \pm 5.91,12.28 \pm 2.66)$ were observed.

\section{References}

1. Anonymous. Ministry of Agriculture and Farmers Welfare, Government of India, 2019. Accessed on 06.03.2019.

2. Ertekin C, Gozlekci, Kabas O, Sonmez S, Akinci I. Some physical, pomological and nutritional properties of two plum (Prunus domestica L.) cultivars. Journal of Food Engineering. 2006; 75:508-514.

3. Ionica ME, Nour V, Trandafir I, Cosmulescu S, Botu M. Physical and chemical properties of some european plum cultivars (Prunus domestica L.). Notulae Botanicae Horti Agrobotanici. 2013; 41(2):499-503.

4. Mahawar MK, Jalgaonkar KR, Kumar M, Meena VS, Bhushan B. Determination of some physical properties of 
date palm fruits (cv. Khadrawy and Medjool). Acta Agrophysica. 2017; 24(2):217-223.

5. Mahawar MK, Bhushan B, Jalgaonkar K, Ghodki BM. Mass modelling of kinnow mandarin based on some physical attributes. Journal of Food Process Engineering. 2019; 42(5). 10.111/jfpe.13079.

6. Mohsenin NN. Physical properties of plant and animal materials. Gordon and Breach Press, New York, USA, 1986.

7. Pathak SS, Pradhan RC, Mishra S. Physical characterization and mass modeling of dried Terminalia chebula fruit. Journal of Food Process Engineering. 2019; 42(3):e12992. https://doi. org/10.1111/jfpe.12992

8. Rop O, Jurikova T, Mlcek J, Kramarova D, Sengee Z. Antioxidant activity and selected nutritional values of plums (Prunus domestica L.) typical of the White Carpathian Mountains. Scientia Horticulturae. 2009; 122(4):545-549.

9. Usenik V, Stampar F, Veberic R. Anthocyanins and fruit colour in plums (Prunus domestica L.) during ripening. Food Chemistry. 2009; 114(2):529-534. 